\title{
LIV. Observations on the crystalline form, \&c. of the Gaylussite
}

\section{W. Phillips F.L.S. G.S.}

To cite this article: W. Phillips F.L.S. G.S. (1827) LIV. Observations on the crystalline form, \&c. of the Gaylussite , Philosophical Magazine Series 2, 1:4, 263-266, DOI: $10.1080 / 14786442708675583$

To link to this article: http://dx.doi.org/10.1080/14786442708675583

册 Published online: 10 Jul 2009.

Submit your article to this journal

Q View related articles $₫$ 
Mr. Phillips on the Crystalline Form of the Gaylussite. 263 circle) $v m n$, to find the hypothenuse $m v$ (or true zenith-distance of the mark $m$ ).

Were fluids indeed subjected, as we have hitherto sup. posed, to the sole action of gravity, our explanation of the theory of the spirit-level might be considered as complete; but from the effect of the mutual attraction of glass and the liquid of the level, the figure \&c. of the bubble, as we shall proceed tơ demonstrate, must suffer material alterations.

[To be continued.]

LIV. Observations on the Crystalline Form, \&c. of the Gaylussite. By W. Philutps, F.L.S. G.S. \&.c.*

$\mathrm{N}$ the Ann. de Chim. for March 1826, is inserted an account and analysis of a mineral newly discovered in a natronlake in Colombia, by M. Boussingault, followed by a description of its crystalline forms, by M. Cordier. It appears to be a hydrous carbonate of lime and soda; consisting of Carbonate of soda 33.96, Carbonate of lime 31.39 , Water 32.20 , Carbonic acid $1 \cdot 45$, and Alumine $1 \cdot 0$, according to M. Boussingault. It has received the name of Gaylussite, in honour of the celebrated French chemist M. Gay-Lussac.

Five crystals of this substance have been presented to me by my brother, who lately received them from Robert Stephenson, a gentleman connected with the establishment of the Columbian Mining Company. One only of these crystals is what may be termed symmetrical in its form, the rest being elongated and channelled on their surfaces in a very remarkable manner. M. Cordier also appears to have possessed only one regularly-formed crystal; but as this was not, as he observes, sufficiently bright for the use of the reflective goniometer, he was compelled to rely on the common one for the measurement of its planes. Mine, on the contrary, is remarkably brilliant, and even transparent: I submitted it therefore to the former instrument, which confirms the most important measurements by M. Cordier.

The primary form adopted by M. Cordier is an irregular octohedron; but finding, as he observes, that " it is not easy to make it clearly appear how the planes of these crystals relate to that form as their primary," he has substituted, " as being more simple, and as Haüy had done in analogous cases, an oblique prism." The measurements and cleavages of these crystals have led me to the conclusion, that the primary is in reality an oblique rhombic prism, but of different measure-

* Communicated by the Author. 
264. Mr. Phillips on the Crystalline Form of the Gaylussite.

ments to that of M. Cordier, and altogether constituted of different planes; that which is adopted by that gentleman does not coincide with the cleavages of the mineral, while that which I propose is bounded by them: the terminal planes decline from one acute angle of the prism to the other.

The planes $e e^{t}$ of the following figures have been adopted by $\mathbf{M}$. Cordier as the lateral planes of his primary prism, and the plane $c$ (if I understand his statement correctly), as the terminal plane.-Slight, but very uncertain indications of cleavage exists in the direction of the latter, but none parallel to the former; while cleavages parallel to the planes $M$ M are easily obtained, and of uncommon brilliancy; and parallel to P, I have obtained a cleavage sufficiently bright for the use of the reflective goniometer.

Fig. 1.

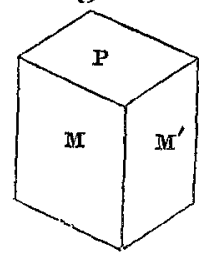

Fig. 2.

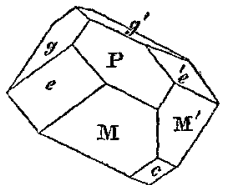

Fig. 3.

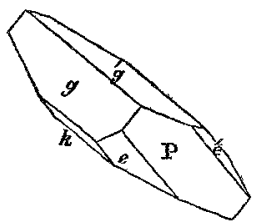

Measurements by the reflective Goniometer.

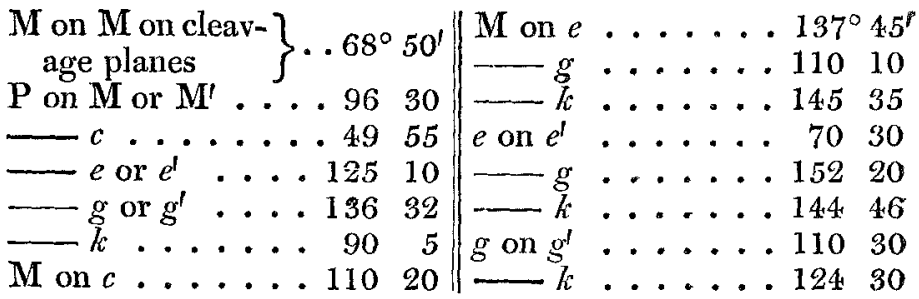

The crystals do not occur in the determinate form of fig. 1 , but are generally elongated, owing to the increased dimension of the planes $g, g$, thus greatly reducing the planes $M M^{\prime}$, or annihilating them, as in fig. 2 : the crystals are often still further elongated, by narrow and repeated alternations of portions of the plane $e e^{\prime}$, and $g, g^{\prime}$, thus giving them the effect of being deeply grooved, or channelled.

As no description of this mineral has yet appeared, as I believe, in any one of our Journals, I subjoin the following, chiefly extracted from the accounts given by MM. Boussingault and Cordier.

It occurs in detached crystals, disseminated in clay; the less perfect of them might readily be mistaken for crystals of selenite,- the more perfect and smooth have more nearly the 
aspect of calcareous spar: the latter are colourless and transparent, and are doubly refractive in a high degree : in respect of hardness, this substance is between the two above mentioned. Spec. grav. 1.928, 1.950; but that of the remarkably brilliant and solid crystal above figured, was found by my friend S. L. Kent to be 1.990 . It is extremely brittle; is ea.sily reduced to a grayish powder; the cross fracture is conchoidal, and the surfaces produced by it are of a vitreous lustre. The crystals are neither phosphorescent by firiction, nor electric by heat; nor does any phosphorescence appear if the powder be thrown on a live coal. When exposed to heat in a matrass, it decrepitates slightly and becomes opaque: decrepitation continues until it has acquired a red heat; if then subjected to the flame of the blowpipe, it melts rapidly into an opaque globule, which once formed, is infusible; and which if placed on the tongue when it is cold, has a deciderlly alkaline taste. In nitric acid it dissolves with brisk effervescence, and if then left to spontaneous evaporation, fine crystals of nitrate of soda are formed, floating in a solution of nitrate of lime.

This mineral is found in great abundance near Lagunilla, a little Indian village, situated one day's journey S.W. of the city of Merida. It occurs disseminated at the bottom of a small lake in a bed of clay covering carbonate of soda, termed by the natives urao, which has been described by M. Palacio Faxar, in a Memoir inserted in the first volume of the Institution Journal. The natives term the crystals of Gaylussite clavos (nails), from their general form, doubtless, when greatly elongated. A specimen of the urao was likewise received by my brother. It occurs in long slender crystals, which are very indeterminate and dull, but affording one bright cleavage parallel to their axis : they radiate from a common centre.

The following particulars respecting the relative positions of the Gaylussite and Urao are extracted from the letter received by my brother with the specimens.

The lake of Laguilla (Lagunilla, Boussinganlt; Lalagunilla, Faxar) is about two days journey from the southern extremity of the lake of Maracaibo: it seldom exceeds six feet in depth : the water reposes on a stratum of black slimy mud in which the crystals of Gaylussite are disseminated. Below the mud, which varies from 18 inches to two feet or upwards in thickness, appears the upper layer of urao, confusedly crystallized, and varying from two to four inches in thickness. It is extracted by expert divers, who can remain a long time under water; they guide themselves, when diving, by a long pole which they stick into the mud, where they expect to be

Nere Series. Vol. 1. No. 4. April 1827. $2 \mathrm{M}$ suc- 
successful. The divers told me that there are other and inferior strata of urao and mud alternating to a depth which they could only reach by extraordinary exertions. The urao is used by the natives to give pungency to their tobacco, by steeping it in a solution. Smoking cigars thus prepared produces soreness of the mouth, really amounting to a slight salivation. The inhabitants in the vicinity of the lake use a preparation of this salt worked into a paste, with tobacco, and which they call chimo, carrying it in a small box slung round the neck, and occasionally rubbing the nauseous mixture upon the gums and tongue, - a practice which appears to be of Indian origin. According to the analysis of Boussingault, this salt differs in no respect from that of natron.

M. Palacio Faxar says (R. I. J. vol. vi. p. 192) that the urao was analysed by Gray-Lussac, who found it to be natron in no respect different from that found in the lakes of Egypt and Fezzan.

LV. Nere Phenomena caused by the Effect of Magnetic and Electric Infuence, and Suggestions for ascertaining the Extent of the Terrestrial Magnetic Atmosphere。* By J. H. ABraHAM, F.L.S.

To the Editors of the Philosophical Magazine and Annals of Gentlemen, Philosophy.

THE subject of this paper is, generally speaking, one that has been till lately less understood than any other in natural philosophy.

It is a branch of science of which I have attempted to gain some knowledge by numerous and often repeated experiments. It is a branch of science so intricate in its laws and subtile in its effects, that we can make but little progress in it without experiment; and as it is a subject which has of late excited intense interest, it is presumed that the following observations and suggestions may not be deemed unworthy of insertion in your valuable Journal.

Active magnetism may be communicated to, or more correctly concentrated in, a bar of steel of any form, by rubbing one of its sides only, and the power will be found to be equal on any part of its surface at the same distance from the equator of the bar or magnet.

* Communicated by the Anthor. Part of this paper has been read before the Royal Society; and the whole was read before the Sheffield Literary and Philosophical Society in August 1826 .

Magnetism, 